\title{
The use of a continuous flow gradient for the separation of inorganic anions on a monolithic disk
}

\author{
Pavel N. Nesterenko* and Marina A. Rybalko \\ Department of Chemistry, M. V. Lomonosov Moscow State University, 119992 Moscow, Russian Federation. \\ Fax: +7 095939 4675; e-mail: PavelN@analyt.chem.msu.ru
}

DOI: 10.1070/MC2004v014n03ABEH001914

The continuous flow gradient and its effect on chromatographic parameters were investigated for the separations of inorganic anions on a monolithic porous disk with bonded hydroxyproline residues.

The general definition of high-performance liquid chromatography assumes a maximum number of resolved chromatographic peaks in the shortest possible time. There are two main approaches to high-speed ion-chromatography (IC). One is the use of short columns $(3-5 \mathrm{~cm})$ packed with fine particles $1.5-3.0 \mu \mathrm{m}$ in diameter. ${ }^{1}$ A reasonable efficiency can be achieved with such columns in a short time, but a high backpressure does not allow a significant increase of the flow-rate of the eluent and hence a further decrease of the analysis time.

Another possibility for achieving fast IC consists in the use of monoliths or continuous stationary phases. Monoliths have through pores, which result in a low backpressure, and mesopores providing a large surface area. The pores are highly interconnected and form a network of channels, ${ }^{2}$ which allow a very large increase in flow-rate with little loss in efficiency, thus drastically reducing the time of analysis. For a monolithic column $5 \mathrm{~cm}$ in length with an internal diameter of $4.6 \mathrm{~mm}$, the flow-rate can be increased up to $16 \mathrm{ml} \mathrm{min}^{-1}$ providing the separation of a mixture of anions in a minute. ${ }^{3}$

Of course, gradient elution can also be used to reduce the time of chromatographic analysis. A rarely used alternative approach of flow programming has very limited applications in HPLC with packed columns because of a sharp increase of the backpressure, which limits the flow-rate to a relatively narrow range. ${ }^{4,5}$ Note that a flow gradient can often be used only in tandem with a temperature gradient, $, 6,7$ which diminishes the growth of backpressure.

Schafer et al. ${ }^{8}$ considered flow-gradient elution on monolithic silica-based Chromolith (Merck) columns with the use of a sharp increase in the flow rate to speed up the elution of one or two strongly retained peaks, which are widely separated from others on an isocratic chromatogram. The programming of flow-gradient elution for separation on monolithic columns could be more efficient. We studied the separations of inorganic anions on a chemically modified monolithic column with programmed flow gradients during the entire run.

We used a Shimadzu LC-10AT pump (Germany) with programmed eluent flow rate, a Rheodyne 7125 injection valve (USA) and CD-510 conductivity detector (Aquilon, Moscow, Russia). The $\mathrm{CIM}^{\circledR}$ (Convective Interaction Media) disk mono-

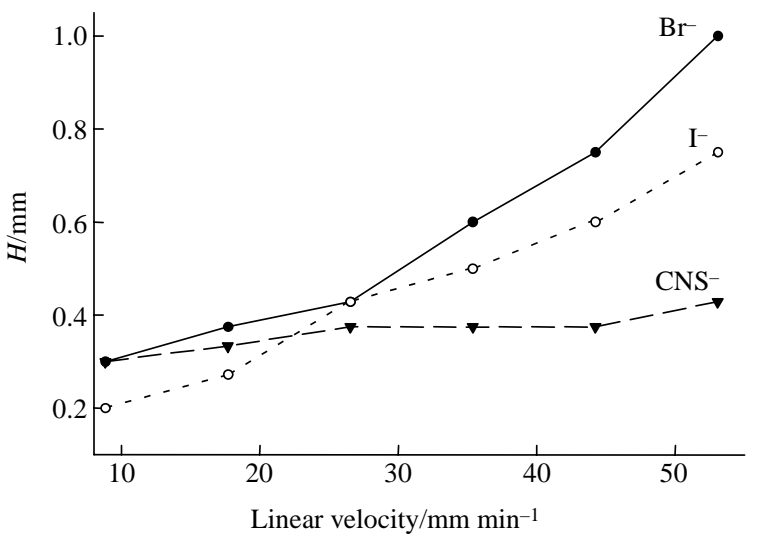

Figure 1 The van Deemter curves for bromide, iodide and thiocyanate. Eluent: $5 \mathrm{mmol} \mathrm{dm}{ }^{-3}$ succinic acid. lithic column consisted of a CIM ${ }^{\circledR}$ Epoxy disk (thickness, $3 \mathrm{~mm}$; diameter, $16 \mathrm{~mm}$; active bed volume, $0.34 \mathrm{ml}$; macropore diameter, $1500 \mathrm{~nm}$; mesopore diameter, $100 \mathrm{~nm}^{9}$ ) and a $\mathrm{CIM}^{\circledR}$ housing (BIA Separations, Slovenia).

L-Hydroxyproline (Sigma) $\left(\mathrm{p} K_{1}=1.92 ; \mathrm{p} K_{2}=9.73\right)$ was chosen as an ion-exchange functionality because of the tertiary nature of the amino group in the bonded state, which provides anion-exchange properties and high ion-exchange selectivity. ${ }^{10,11}$ The attachment of L-hydroxyproline to the disk was performed as described elsewhere. ${ }^{10}$ The dynamic binding capacity of the prepared ion-exchange disk was $0.42 \mu \mathrm{mol}$ per disk on nitrate.

The anion-exchange properties of a disk modified by the amino acid $\left(\mathrm{CIM}^{\circledR}\right.$-HyPro) were studied in relation to the eluent, its concentration and $\mathrm{pH}$. Organic acids at a concentration of $5 \mathrm{mmol} \mathrm{dm}^{-3}$ with native $\mathrm{pH}$ were checked for elution of inorganic anions. The elution power decreases in the order malonic $>$ acetic $>$ citric $>$ succinic $>$ glycolic. As expected, a dilute eluent causes a stronger retention of anions than a more concentrated one.

The $\mathrm{pH}$ of the eluent strongly affects the retention of anions. In the range of $\mathrm{pH} 3.0-4.6$ with succinic acid as the eluent an increase in $\mathrm{pH}$ causes a decrease in the retention of all inorganic anions. The elution order did not change for the anions, except for nitrite. The selectivity of the prepared anion exchanger is similar to that observed earlier for silica-bound hydroxyproline. ${ }^{10,11}$

The dependence of the height equivalent to a theoretical plate (HETP, $H$ ) on linear flow velocity was studied. The maximum efficiency of the $\mathrm{CIM}^{\circledR}$-HyPro disk is about 15 theoretical plates per disk or 5000 theoretical plates per meter for inorganic anions (Figure 1). The efficiency decreases remarkably with increasing flow-rate; this fact should be taken into consideration in flow-gradient separation.

Due to the hydrodynamic properties of monolithic columns, that is, the ability to purge a mobile phase with a high flow-rate and low backpressure, it is possible to apply a flow gradient over a wide range of flow. Hypothetically, the use of a continuous flow gradient throughout the chromatographic run should be more favourable for decreasing the run time but not for improving the efficiency. At a constant eluent composition, the part time of separation should be performed under higher flow rates, which are less suitable for obtaining better efficiency (Figure 1).

To compare the continuous flow-gradient technique with a constant flow mode, a CIM ${ }^{\circledR}$ disk having high permeability was used. At a flow-rate of $5 \mathrm{ml} \mathrm{min}^{-1}$, the column backpressure was less than 30 bar. At a constant flow-rate of $1 \mathrm{ml} \mathrm{min}^{-1}$, which was found optimal from a van Deemeter curve, the separation of three anions was performed on the $\mathrm{CIM}^{\circledR}$-HyPro disk in 40 min [Figure 2(a)]. The same mixture of anions was run with a smooth flow gradient from 1 to $4 \mathrm{ml} \mathrm{min}^{-1}$ [Figure 2(b)]. With gradient, the run time was shortened by a factor of $2-3$; the peak height was increased four times.

The decrease of the separation efficiency at a high flow-rate can be connected with column and extra-column band broadening. ${ }^{3}$

The flow-gradient separation can be considered as a kind of isocratic separation in respect to a constant composition of the 

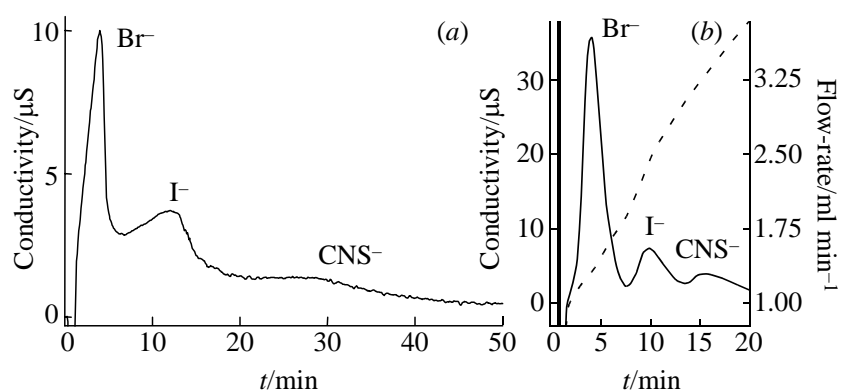

Figure 2 Separation of bromide, iodide and thiocyanate $(a)$ without and (b) with flow gradient. Eluent: $5 \mathrm{mmol} \mathrm{dm}-3$ succinic acid. The profile of the flow gradient is shown by a dotted line. Detection: conductivity. Analyte concentrations, $2 \mathrm{mmol} \mathrm{dm}^{-3}$; sample volume, $5 \mu \mathrm{l}$.

eluent used. Theoretically it means the constancy of a distribution coefficient in the chromatographic system under condition of reasonably good mass transfer. It gives a possibility to calculate the separation efficiency $N$ achieved in both flowgradient and non-flow-gradient elution. For this purpose, the term of the retention time $t_{\mathrm{R}}$ of a solute should be replaced by the retention volume $V_{\mathrm{R}}$, and the peak width should be measured as the volume of the eluent passed through the column for the corresponding time. The relative standard deviation (RSD) of the retention volume is lower than $3 \%$, which confirms a sufficient constancy of the distribution coefficient and the applicability of this approach to calculations of retention parameters in case of flow gradients.

The calculated separation efficiency $(N)$ and peak resolution $\left(R_{\mathrm{S}}\right)$ with and without a flow gradient are presented in Table 1. These data show an abnormal twofold increase of efficiency when a smooth flow gradient is applied. A similar effect was also noted for peak resolution.

Indirect evidence for more efficient separation at higher flowrates apart from the minimum of a van Deemter curve was reported elsewhere. ${ }^{12}$ Sugrue et al. ${ }^{12}$ obtained a convex-type
Table 1 The effect of a flow gradient on the column efficiency $(N)$ and resolution $\left(R_{\mathrm{S}}\right)$.

\begin{tabular}{lllll}
\hline \multirow{2}{*}{ Anion } & \multicolumn{2}{l}{ Without flow gradient } & \multicolumn{2}{l}{ With flow gradient } \\
& $N^{a}$ & $R_{\mathrm{S}}$ & $N^{a}$ & $R_{\mathrm{S}}$ \\
\hline Bromide & 15.0 & 0.59 & 15.1 & 0.83 \\
Iodide & 12.5 & 0.48 & 22.2 & 0.71 \\
Thiocyanate & 12.3 & - & 28.0 & - \\
\hline
\end{tabular}

${ }^{a}$ The number of theoretical plates per disk.

dependence for the right branch of the van Deemter curve plotted from data on the retention of alkaline earth cations on a porous silica monolith with immobilised iminodiacetic acid. The convex dependence suggests the possibility of better chromatographic efficiency at higher eluent flow-rates.

We are grateful to BIA Separations for providing us with $\mathrm{CIM}^{\circledR}$ disks.

\section{References}

1 D. Connolly and B. Paull, J. Chromatogr. A, 2002, 953, 299.

2 A. Podgornic, M. Barut and A. Strancar, Anal. Chem., 2000, 72, 5693.

dois 3 P. Hatsis and C. A. Lucy, Anal. Chem., 2003, 75, 995.

ㅁiᅧ 4 L. Gonzalez, G. Yuln and M. G. Volonte, J. Pharm. Biomed. Anal., 1999, 20, 487.

5 A. Ramaiya and H. T. Karnes, J. Chromatogr. B., 1997, 691, 119.

6 L. K. Moore and R. E. Synovec, Anal. Chem., 1993, 65, 2663.

F. Houdiere, P. W. J. Fowler and N. M. Djordjevic, Anal. Chem., 1997, 69, 2589.

8 C. Schafer, K. Cabrera, D. Lubda, K. Sinz and D. Cunningham, Am. Lab., 2001, 33, 25.

9 Web page: http://www.biaseparations.com.2003.

10 P. N. Nesterenko, J. High Resolut. Chromatogr., 1991, 14, 767

doi> 11 P. N. Nesterenko, J. Chromatogr., 1992, 605, 199.

doi>12 E. Sugrue, P. Nesterenko and B. Paull, Analyst, 2003, 128, 417.

Received: 4th March 2004; Com. 04/2240 